\title{
Liver disease during and after hematopoietic stem cell transplantation in adults: a single-center Egyptian experience
}

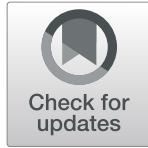

\author{
Haitham Abdelbary * (D), Rasha Magdy, Mohammed Moussa and Inas Abdelmoaty
}

\begin{abstract}
Background: Hepatic complications are a well-known cause of both early and late mortality and morbidity in hematopoietic stem cell transplant (HSCT) recipients. Early diagnosis and management of hepatic complications is important in order to commence appropriate therapy. Conditioning regimens, acute and chronic graft versus host disease, sinusoidal obstruction syndrome, and infections among others represent major hepatic complications for the transplant recipient. We assessed liver function tests, viral markers, polymerase chain reaction, abdominal ultrasound, portal, and hepatic venous duplex in 88 patients underwent autologous and 102 patients underwent allogeneic transplant as well as liver biopsy in selected patients in this retrospective study and evaluated early and late hepatic complications and their impact on transplant outcome.

Results: The major cause of hepatic injury in allogeneic patients is the conditioning regimen (38.8\%) followed by acute GVHD (14.7\%), after day +100 chronic hepatic GVHD is the primary cause of liver injury which occurred in about $40 \%$ of allogeneic patients. In autologous patients, the first cause of hepatotoxicity is also conditioning regimen involving $27.9 \%$ of patients followed by flare of viral hepatitis in $7.9 \%$ and sepsis in $6.3 \%$ of cases. The prevalence of HCV, HBV, and CMV is 19\%, 16\%, and $8 \%$, respectively.

Conclusion: In our study, conditioning regimens, acute and chronic hepatic GVHD are frequent causes of hepatic injury following allogeneic HSCT while conditioning regimens, flare of viral hepatitis, and sepsis represent the most common causes of hepatic injury following autologous HSCT.
\end{abstract}

Keywords: Hematopoietic stem cell transplantation, Hepatotoxicity, Graft versus host disease, Sinusoidal obstruction syndrome

\section{Background}

Hematopoietic stem cell transplantation $(\mathrm{HCT})$ is a curative modality for a wide variety of hematologic disorders. Over the last decades, the safety of HSCT has been improved and the growing use of haploidentical and cord blood transplantation has made it possible to find suitable allogeneic donors and to expand the HCT to older patients [1].

Early survival after HSCT is dependent on the occurrence of hepatic, cardiac, and pulmonary complications and whether serious infections could be avoided [2].

\footnotetext{
* Correspondence: micorreohaitham@gmail.com

Department of Clinical Hematology and Bone Marrow Transplantation, Ain

Shams University, 56 Ramsis street, Abbasia, Cairo, Egypt
}

Several comorbidity indices have been designed to assess hepatic dysfunction before transplantation, the most frequent is the hematopoietic cell transplantation comorbidity index (HCT-CI) [3].

Clinical data together with radiologic and laboratory tests are used in current practice to evaluate hepatic dysfunction before transplantation. Among these, AST, ALT, and bilirubin are the most commonly considered in clinical practice and in pre-transplantation predictive models $[4,5]$.

In the early post-transplant period, infections, drug toxicity, sinusoidal obstruction syndrome (SOS), and acute graft-versus-host disease (aGVHD) are the most frequent causes of hepatic dysfunction while chronic viral hepatitis, chronic GVHD (cGVHD), and iron 
overload states are the most frequent causes of late liver abnormalities [6].

The aim of this retrospective study was to identify the early and late hepatic complications of hematopoietic stem cell transplantation, the clinical significance of each liver function test abnormality before transplantation, their impact on transplantation outcomes.

\section{Study design}

\section{Patients and control}

The study was a retrospective study that included 190 adult patients who had autologous or allogeneic HSCT between October 2004 and October 2016 at a hematopoietic stem cell transplantation unit at a tertiary hematologic center, after taking informed consent.

Participants were grouped into the following:

Group I: this group included 88 adult patients who underwent autologous HSCT.

Group II: this group included 102 adult patients underwent allogeneic HSCT.

Informed consent was obtained from all participants. The study was conducted in accordance with the stipulations of the local ethical and scientific committees of our tertiary care center and the procedures respected the ethical standards in the Helsinki Declaration of 1964.

\section{Methods}

All patients were subjected to full history taking, clinical examination, laboratory or radiological (pre-, during, or post-) transplant workup.

\section{Pre-transplant workup}

Laboratory

1. Disease-specific labs:

- Bone marrow aspiration, flow cytometry, and cytogenetic study to detect minimal residual disease before transplant.

- Disease-specific labs, e.g., multiple myeloma patient had serum protein electrophoresis and immunoglobulin quantitation.

2. ABO blood type and (HLA typing needed for allogeneic patients only).

3. Infectious disease screening for hepatitis $(\mathrm{A}, \mathrm{B}, \mathrm{C})$ testing, HIV (human immunodeficiency virus), HSV (herpes simplex virus), CMV (cytomegalovirus), and EBV (Epstein-Barr virus) by both serology and PCR (polymerase chain reaction), toxoplasmosis.

4. Laboratory tests to check organ function:- CBC, kidney, and liver function (AST, ALT, alkaline phosphatase, $\gamma \mathrm{GT}$, albumin, total, and direct bilirubin), coagulation profile (PT, PTT, INR), serum ferritin level, and pregnancy test for females in child-bearing period.

5. Liver biopsy in selected cases who had pretransplant liver cirrhosis or fibrosis to assess its grade.

\section{Radiological}

Chest X-ray and pulmonary function tests, echocardiography and electrocardiogram, pelvi-abdominal ultrasound, computed tomography scan (CT Scan) to detect any residual disease before transplantation, MRI (magnetic resonance imaging) on selected part of body according to patient disease, e.g., MRI brain if there was any suspect of CNS infiltration, positron emission tomography (PET) scan to detect any residual disease before transplant mainly done in lymphoma.

\section{During and post-transplant workup Laboratory}

$\mathrm{CBC}$, kidney function, and liver function, (PT, PTT, INR) is done weekly, CMV PCR is done weekly, cyclosporine level is done weekly, hepatitis B, C PCR, and EBV PCR in selected cases, serum ferritin level, bone marrow aspiration and (chimerism needed for allogeneic patients only) in D28, D90, D180, D270, D360, and liver biopsy for histologic confirmation of hepatic GVHD in selected cases who had allogeneic HSCT.

\section{Radiological}

In selected cases, for example, pelvi-abdominal ultrasound, hepatic veins, and portal vein duplex in case of suspecting veno-occlusive disease.

\section{Protocols}

Conditioning regimen, GVHD prophylaxis, and supportive care: the conditioning regimens used for allogeneic HSCT were the following:

1. Busulfan $1 \mathrm{mg} / \mathrm{kg} / 6 \mathrm{~h} \mathrm{PO} \mathrm{(day} 7$ till day 4) in combination with fludarabine $30 \mathrm{mg} / \mathrm{m}^{2}$ (day 6 to 3).

2. Busulfan $1 \mathrm{mg} / \mathrm{kg} / 6 \mathrm{~h} \mathrm{PO} \mathrm{(day} 7$ till day 4) in combination with cyclophosphamide $60 \mathrm{mg} / \mathrm{kg}$ day 3 and day -2 with mesna prophylaxis.

3. TBI one fraction daily (2.5 Gy) for 4 consecutive days in combination with cyclophosphamide 60 $\mathrm{mg} / \mathrm{kg}$ (day -3 and day -2 ) with mesna prophylaxis.

\section{Autologous HSCT}

The conditioning regimens used for autologous HSCT were the following: 
1- Melphalan $200 \mathrm{mg} / \mathrm{m}^{2}$ IVI over $30 \mathrm{~min}$ on day -2 was the standard conditioning regimen used in myeloma patients in our center. Patients with impaired renal functions (Cr.clearance $<30 \mathrm{ml} /$ $\mathrm{min}$ ) received $140 \mathrm{mg} / \mathrm{m}^{2}$ of melphalan.

2. Cyclophosphamide $60 \mathrm{mg} / \mathrm{kg}$ (day -3 and day -2 with mesna as prophylaxis) in combination with etoposide $\left(15 \mathrm{mg} / \mathrm{m}^{2)}\right.$ day -2 and day -1 and carboplatin $400 \mathrm{mg} / \mathrm{m}^{2}$ (day $\left.-3,-2\right)$.

3. Melphalan $200 \mathrm{mg} / \mathrm{m}^{2}($ day -2$)$ and Etoposide $1600 \mathrm{mg} / \mathrm{m}^{2}($ day -2$)$.

\section{GVHD prophylaxis}

In allogeneic patients, GVHD prophylaxis included cyclosporine (CSA) plus methotrexate (MTX). CSA was started on day -1 at a dose adjusted to trough blood levels (between 200 and $300 \mathrm{ng} / \mathrm{mL}$ ). MTX was administered on days $+1,+3,+6$, and $+11\left(10 \mathrm{mg} / \mathrm{m}^{2)}\right.$ followed by folinic acid rescue. In vivo $\mathrm{T}$ cell depletion with antithymocyte globulin (ATG) was used in patients with aplastic anemia mainly.

\section{Supportive care}

Acyclovir, fluconazole/voriconazole, and quinolones (ciprofloxacin or levofloxacin) were administered from day -1 until neutrophil recovery as infectious prophylaxis. CMV screening using PCR for guiding pre-emptive therapy. Galactomannan in blood samples was performed in suspected cases of neutropenic patients who are not responsive to neutropenic fever protocol ursodeoxycholic acid used as prophylactic agent to prevent liver injury.

\section{Hepatic dysfunction}

The medical records of all patients were reviewed and details of serial liver function tests during the pre-transplant and post-transplant period were evaluated. These data were collected and analyzed for specific time periods after transplantation: -1 to 30 days, 31 to 100 days, and 101 to regular follow-up as long as the patient is alive.

For most patients, liver function tests were carried out twice weekly during the first 30 days, were done daily in critically ill patients. Twice weekly during the next 30 to 60 days, once a week after 60 days to 180 days, and every month after 180 days to 1 year. Note was made of relevant clinical findings and subsequent investigations. In case of liver test abnormalities, patients underwent imaging studies (ultrasonography or computed tomography scan) and microbiological studies (CMV antigenemia/ PCR, blood cultures, and other viral PCR studies.

The etiology of abnormal liver function and any therapeutic action taken were recorded and interoperated and classified by using diagnostic criteria of Forbes et al. [7].

(1) Hepatic GVHD: the presence of clinical and histological evidence of GVHD in conjunction with the development of abnormal serum liver biochemistry. Acute and chronic GVHD were divided by a temporal cut-off of 100 days after BMT.

(2) Drug hepatotoxicity:

a. Drug hepatotoxicity from conditioning therapy: transient development of abnormal liver function during the first 2 weeks after BMT in the absence of other identifiable causes.

b. Cyclosporin hepatotoxicity: clinical features of cyclosporin toxicity (for example, fluid retention, hypertension, renal impairment, and tremor) and elevated serum cyclosporin level (whole blood cyclosporin level > $400 \mathrm{mg} / \mathrm{l}$ ) in conjunction with the transient development of abnormal liver function.

c. Hepatotoxicity from other drugs: transient abnormal liver function temporally related to the introduction of a drug known to cause hepatotoxicity.

(3) Viral hepatitis: development of abnormal serum liver enzymes in conjunction with serological evidence of active viral infection.

(4) Sepsis: development of/or deterioration of liver function during an episode of bacterial or fungal sepsis.

(5) Veno-occlusive disease: clinical criteria of venoocclusive disease developed by the Baltimore group were used. The Baltimore criteria include jaundice (bilirubin $>2.0 \mathrm{mg} / \mathrm{dl}$ ) and two of the following: hepatomegaly (usually painful), ascites, or more than $5 \%$ weight gain.

(6) Disease recurrence: development of abnormal liver function at a time of clinical evidence of disease recurrence.

\section{Statistical analysis}

The primary endpoint of the study was to determine the impact of liver function abnormalities on the outcome of autologous and allogeneic HSCT. Secondary endpoints were to classify and describe hepatic dysfunction after transplant, and to determine its frequency and risk factors. The incidences of hyperbilirubinemia, acute GVHD, and chronic GVHD were calculated using cumulative incidence estimates. All statistical analyses were performed using SPSS, version 17.0 (SPSS, Chicago, IL, USA).

\section{Results}

One hundred ninety patients were included in this study (88 patients underwent autologous and 102 underwent allogeneic transplant), the type of disorders and the conditioning regimens used were illustrated in Table 1.

Almost half of the patients had no pre-transplant morbidity followed by multisystem involvement in $23.2 \%$ and hepatic affection in $14.2 \%$ (Fig. 1). Using (abdominal US, CT, 
Table 1 Clinical and laboratory data of patients who had HSCT in the BMT unit

\begin{tabular}{|c|c|c|}
\hline \multicolumn{2}{|l|}{ Variable } & \multirow[b]{2}{*}{$121 / 69$} \\
\hline Sex & Male/female & \\
\hline \multirow[t]{2}{*}{ Type of transplantation } & Autologous & $88(46 \%)$ \\
\hline & Allogeneic & $102(54 \%)$ \\
\hline \multirow[t]{7}{*}{ Type of illness } & Multiple myeloma & $47(24.7 \%)$ \\
\hline & AML & $44(23.1 \%)$ \\
\hline & Lymphoma & $41(21.5 \%)$ \\
\hline & ALL & $30(15.7 \%)$ \\
\hline & Severe aplastic anemia & $16(8.4 \%)$ \\
\hline & Chronic myeloid leukemia & $7(3.7 \%)$ \\
\hline & Myelodysplastic syndrome & $5(2.6 \%)$ \\
\hline \multirow[t]{3}{*}{ Virology pre-transplant } & HBV & $31(16.3 \%)$ \\
\hline & $\mathrm{HCV}$ & $36(19 \%)$ \\
\hline & CMV & $15(8 \%)$ \\
\hline \multirow[t]{4}{*}{ Mobilization protocol } & VAD & $23(22.3 \%)$ \\
\hline & DHAP & $38(36.9 \%)$ \\
\hline & Velcade/dexamethasone & $31(30.1 \%)$ \\
\hline & Endoxan/G-CSF & $38(36.9 \%)$ \\
\hline \multirow{3}{*}{$\begin{array}{l}\text { Conditioning regimen for } \\
\text { autologous transplant }\end{array}$} & Melphalan & $45(51.1 \%)$ \\
\hline & Carboplatin/VP16/CY & $19(21.5 \%)$ \\
\hline & Melphalan/VP16 & 16(14.7\%) \\
\hline \multirow{4}{*}{$\begin{array}{l}\text { Conditioning regimen for } \\
\text { allogeneic transplant }\end{array}$} & $\mathrm{BU}+\mathrm{FLU}$ & $51(50 \%)$ \\
\hline & $\mathrm{BU}+\mathrm{CY}$ & 16(15.6\%) \\
\hline & $\mathrm{TBI}+\mathrm{CY}$ & $13(12.7 \%)$ \\
\hline & $C Y+F L U+A T G$ & $10(9.8 \%)$ \\
\hline
\end{tabular}

or MRI abdomen or PET scan), the main radiological finding was non-specific hepatomegaly followed by fatty livers but most of the patients had no liver involvement (Fig. 2).

Pre-transplant liver injury detected laboratory investigations had a highly statistically significant effect on the liver injury during transplantation (from the onset of conditioning regimen to the time of engraftment) ( $P$ value 0.000 ) (Table 2 ), while pre-transplant liver injury detected laboratory investigations had a statistically insignificant effect on liver post-transplantation (within a 1-year follow-up period) ( $P$ value 0.138 ).

In allogeneic patients during the first 100 days, hepatotoxicity from conditioning regimens occurred in 38.2\% and acute GVHD in $14.7 \%$ while chronic GVHD occurred in $35.3 \%$ (Table 3). In autologous patients, hepatotoxicity from conditioning regimens occurred in $27.9 \%$ and flare of viral hepatitis in $7.9 \%$ (Table 4).

Acute GVHD occurred in 33\% of patients with grade III and IV occurred in $32.2 \%$ and $41.9 \%$, respectively, while chronic GVHD occurred in nearly $70 \%$ of patients with grades II, III, and IV GVHD occurred in 23.2\%, $32.1 \%$, and $37.5 \%$, respectively (Table 5).
Busulfan-based conditioning regimens were the most common regimen associated with hepatotoxicity compared to non-busulfan based regimens with a highly statistically significant difference $(P$ value 0.003) (Table 6).

Chronic hepatic GVHD is the main cause of hepatotoxicity post-transplant with a highly statistically significant difference ( $P$ value 0.00 ), while hepatic hemosiderosis is statistically insignificant with hepatic injury post-transplant ( $P$ value 0.352$)[7]$.

Septicemia had a statistically insignificant effect on the liver during transplant in both autologous and allogeneic patients ( $P$ value 0.881$)$, but it has a highly statistically significant difference between autologous and allogeneic patients post-transplant, with sepsis being higher in allogeneic patients.

\section{Discussion}

Hepatic dysfunction is a common problem in HSCT recipients. Diagnosis can be accomplished by an interpretation of the clinical setting in which liver dysfunction occurs in order to institute appropriate therapy.

In the current study, the prevalence of pre-transplant liver function abnormalities in both allogeneic and autologous patients before conditioning is $11.1 \%$ that increased to $48.8 \%$ after conditioning regimens of which $12.6 \%$ had grade III-IV hepatic dysfunction. The prevalence is similar to a previous report by El-Sayed et al. from Egypt who found that $10 \%$ of patients had mild hepatic dysfunction pre-transplant that increased after conditioning to 47\% [8]. Moreover, the previous report by Wang et al. showed a higher percentage of liver function abnormalities pretransplant $(19.8 \%)$ that increased to $81 \%$ during conditioning regimen [9].

Various observations suggest that patients with hepatic dysfunction before transplantation may be at risk of hepatic disease post-transplant. Others reported that hepatic disease at the time of transplantation did not appear to increase the risk [2].

When we correlated between pre-transplant abnormal transaminase levels and the rise in liver transaminases during transplantation (from day 0 to day +30 ), we found a highly statistically significant difference $(P$ value 0.000). Conversely, we found that the incidence of longterm hepatic complications was independent of abnormal transaminases pre-transplant.

In our study, the major cause of hepatic injury in allogeneic patients is the conditioning regimen (38.8\%) followed by acute GVHD (14.7\%) of which $32.2 \%$ had grade III and $41.9 \%$ had grade IV, respectively. Then similarly, $2 \%$ of patients had a flare of viral hepatitis, sepsis, SOS, or CMV hepatitis. These figures are dramatically changed after day + 100 as chronic hepatic GVHD is the primary cause of liver injury which occurred in about $40 \%$ of allogeneic patients of 


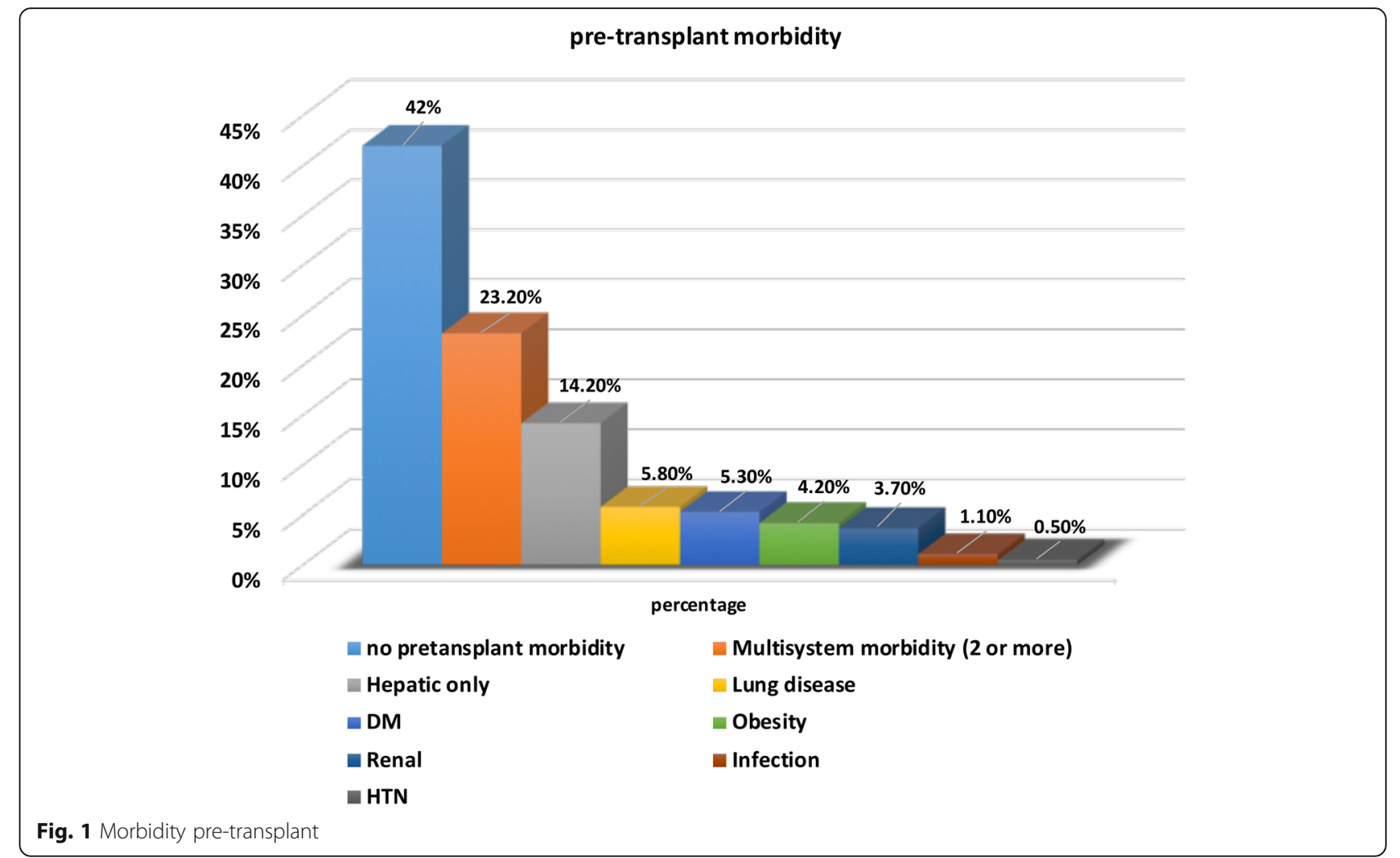

which (7.1\% had grade I, $23.2 \%$ had grade II, 32\% had grade III, and $37.5 \%$ had grade IV) followed by significant decrease of drug-induced hepatotoxicity (3.9\%), iron overload in $2.9 \%$. In autologous patients, the first cause of hepatotoxicity is also conditioning regimen involving $27.9 \%$ of patients followed by a flare of viral hepatitis in $7.9 \%$ and sepsis in $6.3 \%$ of cases. Long-term, drug-induced hepatotoxicity involved $11.4 \%$ of patients and is the major cause of hepatotoxicity.
In a similar study, Barba et al. found that acute hepatic GVHD was found in $17 \%$ of patients who underwent alloHSCT while chronic hepatic GVHD was found in $50 \%$ of their cohort [3]. Another multicenter retrospective study by Battipaglia et al. that included 146 adults with AML and receiving allo-HSCT, the main cause of liver function abnormalities among patients were acute GVHD (31\%), chronic GVHD at 2 years was 25\% [10].

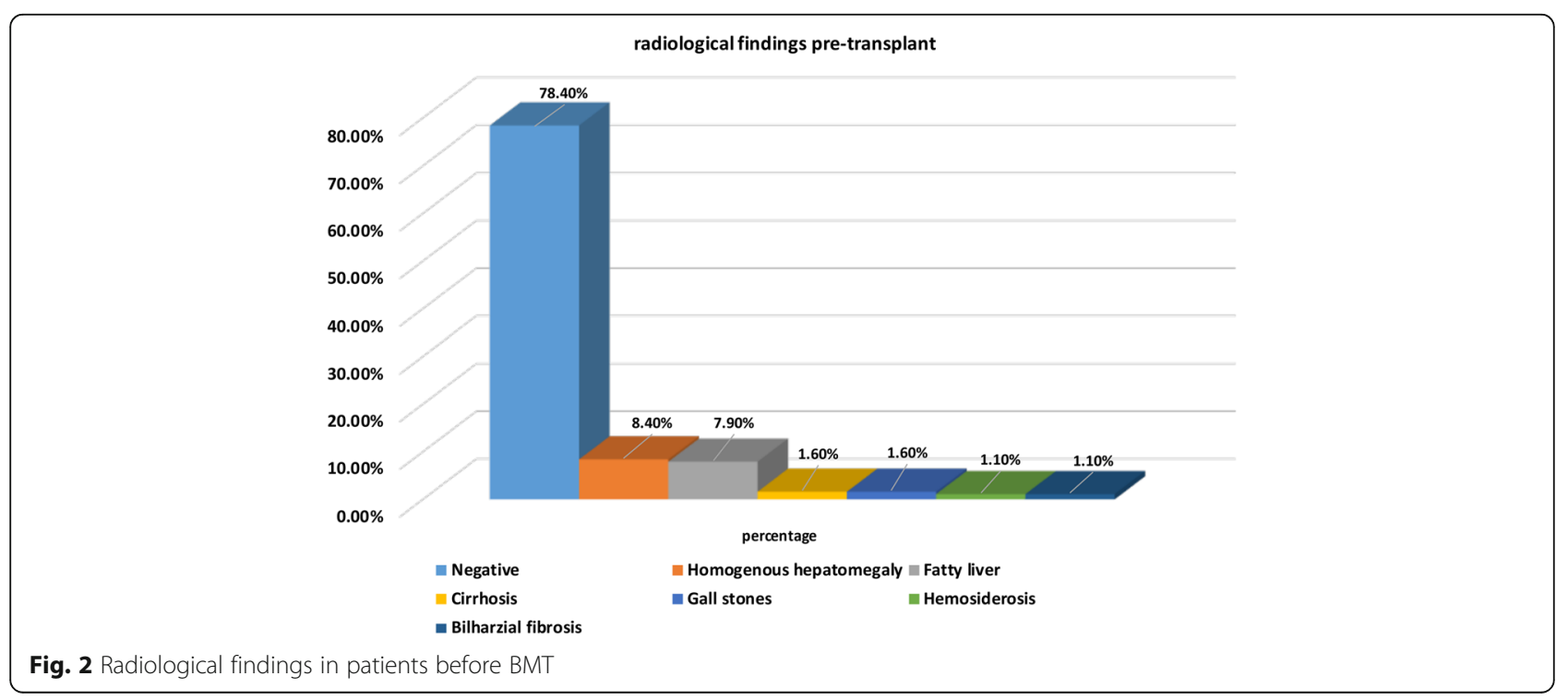


Table 2 Correlation between abnormal laboratory liver functions pre- and during HSCT

\begin{tabular}{|c|c|c|c|c|c|c|}
\hline & \multicolumn{2}{|c|}{ Positive liver injury during transplant } & \multicolumn{2}{|c|}{$\underline{\text { Negative liver injury during transplant }}$} & \multirow[t]{2}{*}{$x^{2}$} & \multirow[t]{2}{*}{$P$} \\
\hline & N & $\%$ & $N$ & $\%$ & & \\
\hline Liver affection pre-transplant (positive) & 37 & 19.4 & 15 & 7.8 & 14.128 & .000 \\
\hline Liver affection pre-transplant (negative) & 56 & 29.4 & 82 & 43.1 & & \\
\hline Total & 93 & 49 & 97 & 50 & & \\
\hline
\end{tabular}

Regarding the type of conditioning regimen and hepatotoxicity, we found that busulfan-based conditioning regimens had a statistically significant hepatotoxic effect compared to non-busulfan conditioning regimens.

The population of Egypt has a heavy burden of liver disease. The overall prevalence of positive antibody testing to hepatitis $\mathrm{C}$ in the general population is around $15-20 \%$ [11]. The prevalence of HCV in our patients is $19 \%$ while the prevalence of $\mathrm{HBV}$ was $16 \%$ and CMV is $8 \%$. Similarly, the previous report by El-Sayed et al. from Egypt with similar environmental factors revealed that the prevalence of pre-transplant $\mathrm{HBV}$ and $\mathrm{HCV}$ in their patients was $27 \%$ and $31 \%$, respectively [8]. The flare of viral hepatitis in both autologous and allogeneic patients represented 3\% of all patients in our study.
In a recent retrospective study by Torres et al. at $\mathrm{MD}$ Anderson who included 59 patients (14 autologous and 13 allogeneic HSCT), all of his patients were HCVinfected recipients, and $\mathrm{HCV}$ reactivation was seen in $11 \%$ of patients infected with genotype 1 ; median time to HCV reactivation was 41 days after transplant [12].

In our study, viral hepatitis reactivation had a statistically insignificant effect on liver injury neither during nor post-transplant in both allogeneic and autologous patients. For patients with HBV, the usage of lamivudine prophylaxis starting before the conditioning regimen might be responsible for the reduced risk of reactivation as previously reported by Lau et al. [13]. Similarly, in a study by Firpi and Nelson, they found that prophylactic lamivudine dramatically reduced the chance of reactivation

Table 3 Etiology of liver injury and abnormal liver function test

\begin{tabular}{|c|c|c|}
\hline \multicolumn{3}{|l|}{ Variable } \\
\hline Abnormal pre-transplant liver function & $\begin{array}{l}\text { Grade I } \\
\text { Grade II } \\
\text { Grade III } \\
\text { Grade IV }\end{array}$ & $\begin{array}{l}14(7.4 \%) \\
7(3.7 \%) \\
-----\end{array}$ \\
\hline Abnormal liver function during transplant & $\begin{array}{l}\text { Grade I } \\
\text { Grade II } \\
\text { Grade III } \\
\text { Grade IV }\end{array}$ & $\begin{array}{l}53(27.9 \%) \\
15(7.9 \%) \\
12(6.3 \%) \\
12(6.3 \%)\end{array}$ \\
\hline Abnormal liver function post-transplant & $\begin{array}{l}\text { Grade I } \\
\text { Grade II } \\
\text { Grade III } \\
\text { Grade IV }\end{array}$ & $\begin{array}{l}44(23.2 \%) \\
15(7.9 \%) \\
5(2.6 \%) \\
10(5.3 \%)\end{array}$ \\
\hline Classification of liver injury in allogeneic patients from D0 to Day +100 & $\begin{array}{l}\text { Drugs/conditioning regimen } \\
\text { Acute GVHD } \\
\text { Flare of viral hepatitis } \\
\text { Sepsis } \\
\text { SOS } \\
\text { CMV hepatitis }\end{array}$ & $\begin{array}{l}39(38.2 \%) \\
15(14.7 \%) \\
2(2 \%) \\
2(2 \%) \\
2(2 \%) \\
2(2 \%)\end{array}$ \\
\hline Classification of liver injury in allogeneic patients after day +100 & $\begin{array}{l}\text { Chronic GVHD } \\
\text { Double pathology } \\
\text { Drugs/conditioning regimen } \\
\text { Flare of viral hepatitis } \\
\text { Iron overload } \\
\text { Sepsis }\end{array}$ & $\begin{array}{l}36(35.3 \%) \\
12(11.8 \%) \\
4(3.9 \%) \\
2(1 \%) \\
3(2.9 \%) \\
2(2 \%)\end{array}$ \\
\hline Classification of liver injury in autologous patients in the early post-transplant period & $\begin{array}{l}\text { Drugs/conditioning regimen } \\
\text { Flare of viral hepatitis } \\
\text { Sepsis }\end{array}$ & $\begin{array}{l}53(27.9 \%) \\
15(7.9 \%) \\
12(6.3 \%)\end{array}$ \\
\hline Classification of liver injury in autologous patients in the late post-transplant period & $\begin{array}{l}\text { Drugs/conditioning regimen } \\
\text { Flare of viral hepatitis } \\
\text { Sepsis }\end{array}$ & $\begin{array}{l}10(11.4 \%) \\
1(1.1 \%) \\
1(1.1 \%)\end{array}$ \\
\hline
\end{tabular}


Table 4 GVHD sites, grades, and liver biopsy

\begin{tabular}{|c|c|c|}
\hline Variable & & \\
\hline Classification of acute GVHD & $\begin{array}{l}\text { Negative } \\
\text { Positive GIT alone } \\
\text { Positive hepatic alone } \\
\text { Positive mucocutaneous alone } \\
\text { Combined } 2 \text { organs or more }\end{array}$ & $\begin{array}{l}63(67 \%) \\
10(10.6 \%) \\
6(6.4 \%) \\
2(2.1 \%) \\
13(13.9 \%)\end{array}$ \\
\hline Grades of acute GVHD & $\begin{array}{l}\text { Grade I } \\
\text { Grade II } \\
\text { Grade III } \\
\text { Grade IV }\end{array}$ & $\begin{array}{l}2(6.4 \%) \\
6(19.3 \%) \\
10(32.2 \%) \\
13(41.9 \%)\end{array}$ \\
\hline Classification of chronic GVHD & $\begin{array}{l}\text { Negative } \\
\text { Positive GIT alone } \\
\text { Positive hepatic alone } \\
\text { Positive mucocutaneous alone } \\
\text { Positive pulmonary alone } \\
\text { Combined hepatic with another system }\end{array}$ & $\begin{array}{l}25(30.9 \%) \\
3(3.7 \%) \\
13(16 \%) \\
5(6.2 \%) \\
2(2.5 \%) \\
33(41 \%)\end{array}$ \\
\hline Grades of chronic GVHD & $\begin{array}{l}\text { Grade I } \\
\text { Grade II } \\
\text { Grade III } \\
\text { Grade IV }\end{array}$ & $\begin{array}{l}4(7.1 \%) \\
13(23.2 \%) \\
18(32.1 \%) \\
21(37.5 \%)\end{array}$ \\
\hline Liver biopsy & $\begin{array}{l}\text { Not done } \\
\text { Positive for GVHD } \\
\text { Positive for iron overload } \\
\text { Combined GVHD and iron overload }\end{array}$ & $\begin{array}{l}65(76.5 \%) \\
14(16.5 \%) \\
2(2.2 \%) \\
4(4.7 \%)\end{array}$ \\
\hline
\end{tabular}

(from $24-53 \%$ to $0-5 \%$ ) and also led to improvement in survival-free from hepatitis [14].

Our results showed that $46.6 \%$ of acute hepatic GVHD patients were $\mathrm{HCV}$ positive. While $16.6 \%$ of patients with chronic hepatic GVHD were HCV+ve and similarly, 16.6\% had HBV infection.

Prevalence of CMV infection in our center in allogeneic patients was $57 \%$ ( most of them were detected with weekly screening for CMV with no evidence of CMV disease for pre-emptive therapy) with reactivation occurred in about $65 \%$ of those who had primary infection, while the prevalence of CMV infection in autologous patients was about $18 \%$. CMV hepatitis reactivation had a statistically insignificant effect on hepatic injury neither during nor post-transplant in both autologous and allogeneic patients. In a retrospective study done by Piukovisc et al., the prevalence of CMV in autologous patients was $24 \%$ [15]. While Panagou et al. studied the prevalence of CMV in allogeneic patients, $48 \%$ of his patients at least developed 1 episode of CMV viremia during the first 90 days posttransplant [16].
The risk of infection in the post-engraftment period is a function of the dynamics of immune reconstitution. Factors that delay immune reconstitution following HSCT are related to the increased risk of infection. The most important factors influencing the speed of immune reconstitution are the immune status before HSCT and the need for additional immunosuppressive treatment. Likewise, additional chemotherapy after HSCT greatly increases the risk of infection [17]. When we correlated between septicemia and hepatic injury between autologous and allogeneic patients, we found that septicemia had no statistically significant effect on liver injury during transplant. On the other hand, a statistically significant effect of septicemia on liver injury post-transplant was observed. Sepsis was higher in allogeneic patients due to prolonged use of immunosuppressive therapy and chronic GVHD.

\section{Conclusion}

Conditioning regimens, acute, and chronic hepatic GVHD in our study are major causes of hepatotoxicity following allogeneic stem cell transplantation while drug-induced

Table 5 Busulfan-induced hepatotoxicity

\begin{tabular}{|c|c|c|c|c|c|c|}
\hline & \multicolumn{2}{|c|}{ Positive injury of the liver during transplant } & \multicolumn{2}{|c|}{ Negative injury of the liver during transplant } & \multirow[t]{2}{*}{$x^{2}$} & \multirow[t]{2}{*}{$P$} \\
\hline & $\bar{N}$ & $\%$ & $\bar{N}$ & $\%$ & & \\
\hline Bu-based conditioning & 26 & 25.5 & 23 & 22.5 & 8.777 & 0.003 \\
\hline Non-Bu conditioning & 13 & 12.7 & 40 & 39.3 & & \\
\hline Total & 39 & 38.2 & 63 & 61.8 & & \\
\hline
\end{tabular}


Table 6 Specific liver injury post-allogeneic transplantation

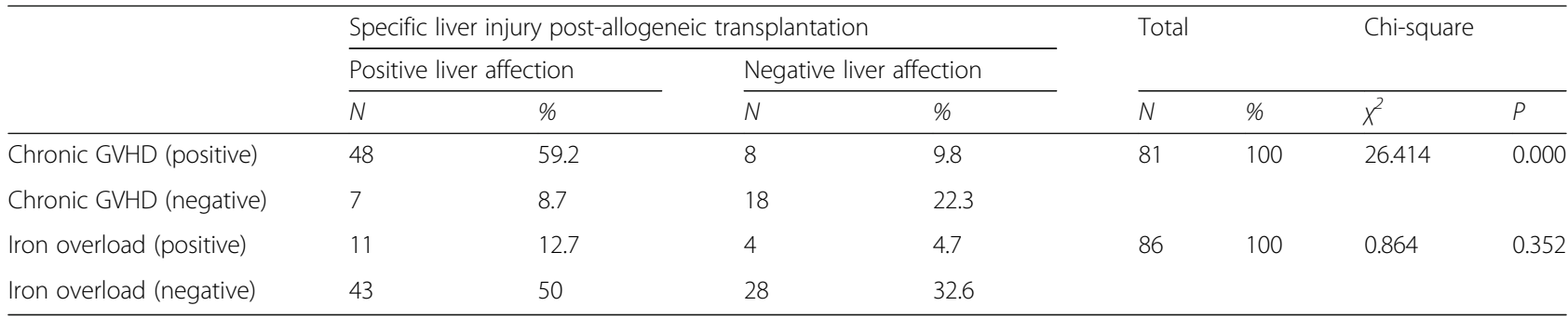

hepatotoxicity, flare of viral hepatitis, and sepsis represent the most common causes of hepatic dysfunction following autologous stem cell transplantation. Determination of liver dysfunction could be determined in many cases with the use of simple non-invasive tests in conjunction with the clinical settings. Effective pre-transplant eradication of viral hepatitis could possibly prevent short and long-term hepatic complications following transplantation.

\section{Abbreviations}

GVHD: Graft versus host disease; HCT-Cl: Hematopoietic cell transplantation comorbidity index; HSCT: Hematopoietic stem cell transplantation; SOS: Sinusoidal obstruction syndrome

\section{Acknowledgements}

Not applicable

\section{Authors' contributions}

MM contributed to the concept. MM, HA, RM, and IA contributed to the design, analysis, and interpretation. IA, HA, and RM helped in data collection and processing. HA and RM contributed to the analysis and interpretation. HA wrote the manuscript. All authors have read and approved the manuscript.

\section{Funding}

No funding was received for this work

\section{Availability of data and materials}

The datasets used and/or analyzed during the current study are available from the corresponding author on reasonable request.

\section{Ethics approval and consent to participate}

Informed written consent was obtained from all participants. The study was conducted in accordance with the stipulations of the local ethical and scientific committees of Ain Shams University and the procedures respected the ethical standards in the Helsinki Declaration of 1964. No ethics committee reference number was provided, instead, a stamped approval was given.

\section{Consent for publication}

Not applicable

\section{Competing interests}

The authors declare that they have no competing interests.

Received: 7 October 2019 Accepted: 31 January 2020

Published online: 22 February 2020

\section{References}

1. Inamoto $Y$, Lee S. Late effects of blood and marrow transplantation. Haematologica. 2017;102(4):614-25.

2. Kim BK, Chung KW, Sun HS, Suh JG, Min WS, Kang CS, et al. Liver disease during the first post-transplant year in bone marrow transplantation recipients: retrospective study. Bone Marrow Transplant. 2000;26:193-7.

3. Barba P, Piñana JL, Fernández-Avilés F, Perez-Simón JA, Martino R, LópezGuerrro E, et al. Pretransplantation liver function impacts on the outcome of allogeneic hematopoietic stem cell transplantation: A study of 455 patients. Biol Blood Marrow Transplant. 2011;17:1653-61.

4. Sorror ML, Maris MB, Storb R, Baron F, Sandmaier BM, Maloney DG, et al. Hematopoietic cell transplantation (HCT)-specific comorbidity index: a new tool for risk assessment before allogeneic HCT. Blood. 2005;106:2912-9.

5. Parimon T, Au DH, Martin PJ, Chien JW. A risk score for mortality after allogeneic hematopoietic cell transplantation. Ann Intern Med. 2006;144:407-14.

6. Arat M, Idilman R. Hepatic complications of allogeneic hematopoietic cell transplantation. Turk J hematol. 2008;25:111-23.

7. Forbes G, Davies J, Herrmann R, Collins BJ. Liver disease complicating bone marrow transplantation: a clinical audit. J Gastroenterol Hepatol. 1995;10:1-7.

8. El-Sayed MH, El-Haddad A, Fahmy OA, Salama I, Mahmoud HK. Liver disease is a major cause of mortality following allogeneic bone marrow transplantation. Eur J Gastroenterol Hepatol. 2004;16(12):1347-54.

9. Zhao J, Ren H, Qui Z, Wang M, Liu W, Xu W, et al. The influence of liver dysfunction before transplantation and during conditioning period on the outcome of allogeneic hematopoietic stem cell transplantation. Zhonghua Nei Ke Za Zhi. 2014;53(2):99-103.

10. Battipaglia G, Labopin M, Candoni A, Fanin R, El Cheikh J, Blaise D, et al. Risk of sinusoidal obstruction syndrome in allogeneic stem cell transplantation after prior gemtuzumab ozogamicin treatment: a retrospective study from the acute leukemia working party of the EBMT. Bone Marrow Transplant. 2017:52(4):592-9.

11. Abdel-Aziz F, Habib M, Mohamed M, Abdel-Hamid M, Gamil F, Madkour S, et al. Hepatitis $C$ virus infection in a community in the nile delta:population description and HCV prevalence. Hepatology. 2000;32:111-5.

12. Torres HA, McDonald GB. How I treat hepatitis $C$ virus infection in patients with hematologic malignancies. Blood. 2016;128(11):1449-57.

13. Xunorong L, Yan A, Liang R, Lau GK. Hepatitis B virus (HBV) reactivation after cytotoxic or immunosuppressive therapy-- pathogenesis and management. Rev Med Virol. 2001;11(5):287-99.

14. Firpi RJ, Nelson DR. Viral hepatitis: manifestations and management strategy. Hematology Am Soc Hematol Educ Program. 2006:375-80.

15. Piukovics K, Terhes G, Gurbity-Pálfi T, Bereczki A, Rárosi F, Deák J, et al. Cytomegalovirus infection in patients with hematological diseases and after autologus stem cell transplantation as consolidation: A single center study. Ann Hematol. 2017;96(1):125-31.

16. Panagou E, Zakout G, Keshani J, Smith C, Irish D, Mackinnon S, et al. Cytomegalovirus pre-emptive therapy after hematopoietic stem cell transplantation in the era of real-time quantitative PCR: comparison of recipients of solid organ transplants. Transpl Infect Dis. 2016;18(3):405-14.

17. Nucci M, Anaissie E. Infections after high-dose chemotherapy and autologus hematopoietic stem cell transplantation. In: Maschmeyer G, Rolston KV, editors. Infections in hematology. 1st ed. Heidelberg: Springer-Verlag Berlin Heidelberg; 2015. p. 49-61.

\section{Publisher's Note}

Springer Nature remains neutral with regard to jurisdictional claims in published maps and institutional affiliations. 